\title{
The Impact of Critical Success Factors for Implementing Knowledge Management on the Deanships at King Abdulaziz University in Jeddah
}

\author{
Shaymaa Mousa \\ Business and Administration Faculty \\ King Abdulaziz University
}

\author{
Amal Salem Bin Mahfouz \\ Business and Administration Faculty \\ King Abdulaziz University
}

\begin{abstract}
Knowledge is considered a modern science in the world and especially in the Arab world. Thus, there is a notable lack of research in the field of knowledge management and management applications. This lack has motivated the author to undertake research in the field of knowledge management. This study revolves knowledge management and Critical Success Factors by studying effect the final on the first. The goal of this research is to determine the impact of Critical Success Factors for implementing knowledge management on the Deanships at King Abdul-Aziz University in Jeddah. The research community is comprised of administrators in the Deanships and totaled 1,207 individual. This study used a random sampling method. The most important results is that based on the weighted mean of Critical Success Factors, the priority order of the factors are Human Resource Management; Information Technology Infrastructure; Leadership; Training; Strategy; Organizational culture, Structure, Roles, and Responsibilities; and finally Performance Measurement.
\end{abstract}

\section{Keywords}

Knowledge, Knowledge Management, Critical Success Factors.

\section{INTRODUCTION}

The 21 st century is characterized by a wealth of widely available information. Information is the foundation of knowledge and its widespread availability has helped increase the growth of knowledge for a variety of organizations more than ever before. Knowledge is the human understanding of a specialized field of interest that has been acquired through study and experience [7].In this context, knowledge can be classified as tacit and explicit knowledge. This classification is important for organizations responsible for knowledge management $(\mathrm{KM}) . \mathrm{KM}$ is the process of knowledge creation, codification, sharing and understanding how these activities promote learning and innovation [7]. KM focuses on the creation and organization of obtainable knowledge when it is needed, from any source and at any time. Hence, KM increases efforts to obtain and dissemination important knowledge that exists in the minds of experienced personnel in the organization. [10] KM benefits both individuals and the organization.

In this context, KM has two basic components: KM solutions and $\mathrm{KM}$ foundations.KM solutions focus on the method through specific aspects of KM can be achieved, such as KM processes and KM systems. KM foundations focus on the broad organizational features that support KM. Foundations for $\mathrm{KM}$ are comprised of $\mathrm{KM}$ infrastructure, $\mathrm{KM}$ mechanisms, and $\mathrm{KM}$ technologies. [10] Knowledge has become important in all domains. Therefore, it is related to several concepts, the most important of which is the concept of intellectual capital. "An organization's intellectual capital refers to sum of all its knowledge resources, which exist in aspects within or outside the organization."[10] There are three types of intellectual capital: human, organizational, and social capital. [10]Critical success factors (CSF) affect the application of KM in various organizations. CSFs can be defined as "areas in which results, if they are satisfactory, will ensure successful competitive performance for the organization" [8].Studies that attempt to identify CSFs apply a variety of approaches. The methodologies vary depending on location and sample. After reviewing previous studies, the author adopted CSFs that fit with university environment includes strategy, leadership, organizational culture, structure, roles and responsibilities, human resource management, training, information technology (IT) infrastructure and performance measurement.

In general, knowledge is considered a modern science in the world and especially in the Arab world. Thus there is a notable lack of research that enriches knowledge and its management applications. This lack of research has motivated the author to investigate the field of KM. It is hoped that this research will contribute to the dissemination of the concept of $\mathrm{KM}$ among the staff of the organization. This paper focuses on the importance and effectiveness of their application in organization and contributes to the general enrichment of research in this field.

This research measures the impact of CSFs for implementing $\mathrm{KM}$ at King Abdul-Aziz University (KAU). KM is very important in the organization. It should be noted that this research is considered the first in Saudi Arabia to address CSFs in relation to KM.

\section{RELATED WORK}

Through a survey for previous Studies, found that researchers touched to the field of knowledge management and systems. This are applied in at different places such as hospitals, organizations and universities. The following has Narrative for these studies on two groups. The first based on their relationship to the management of administrative knowledge and the second based on their relationship to critical success factors:Studies related to Knowledge Management are Morrison Propose the possibility that the presence of shared erroneous knowledge influences the level of users trust. Therefore, research revolves around three points: Trust, Trust and Knowledge Management Systems, and Expertise Locator Systems. Rotter defined trust as "an expectancy held by an individual or a group that the word, promise, or verbal or written statement of another individual or group can be relied upon". The researcher explained that knowledge is one corporate asset that can be both difficult to obtain. Knowledge can be referred to as the product of human learning .Knowledge assets are generally held to be among the most critical to corporate success. The researcher reached that the accuracy of knowledge shared by experts through an expert locator system will be positively related to users trust. In 
addition, they pointed out that continuous use of a knowledge management system by novices increases the ability to identify possible gaps in organization knowledge. Shadi and Maziar identify any effect of knowledge management processes on innovation capacity. This study tries to shed light the relationship between knowledge management processes and innovation capacity in manufacturing factories. There are seven processes of knowledge management include knowledge creation, knowledge organization, knowledge dissemination, knowledge application, knowledge identification, knowledge storage, and knowledge collection. The researcher also noted that knowledge management considered as a continuous process to serve the organization's needs. This has resulted to that four of seven processes of knowledge management (knowledge creation, knowledge organization, knowledge dissemination, and knowledge application) were strongly associated with factories innovation capability. Other three knowledge management factors (knowledge identification, knowledge storage, and knowledge collection) that were recognized as factors not associated with those factories innovation capability. Mihaela Propose the architecture of a multi agent system developed for university research activity monitoring as a knowledge management tool. Preliminary results of a prototype system run are briefly discussed. The researcher talked about the main purpose of the multi-agent system is to provide real information about the current state of the university research activity for the dynamic adaptation of the knowledge management strategy in order to improve the university ranking position.

The researcher concluded that the proposed system can be integrated in the university knowledge management system. As well as, it can be used as a decision support tool for the adoption of new strategies for the research activity improvement. It is also provides the weak and strong points of the research activity done in a certain period. U Syed Aktharsha et al. Aim to examine the impact of Organizational Trust (OT) within KM context. This study focuses on validating the research model developed by Sabrina and Matthew and Its applicability in the Indian hospital context. This model explains that Organizational Trust significantly influences Social Factor, Affect, Perceived Usefulness and Perceived Ease of Use. As well as, Social Factors, Affect, Perceived usefulness, Perceived ease of use and Facilitating conditions influences the KM system usage behavior for Knowledge Sharing( KS).The result, it was established that OT could affect those Important predictors belonging to poignant control. In addition, organizations should try to generate an encouraging societal setting in order to increase the intention to use or real usage behavior. Furthermore, they pointed that Social influence from the top management play a significant role in the direction of the behavior. JUDE et al propose a theoretical approach for integrating KM technologies in higher education processes with a view to achieving enhanced performances. In this context, Researchers depend on Task-technology fit theory and integrative learning and performance architecture. Our proposed approach thus helps to clarify the connection between organizational learning, enabling technologies, KM processes and leadership. Finally, the main intention between the use and integration of KM technologies in teaching and learning is often to change how teaching, learning and research are conducted in the sense of putting more emphasis on interactions, flexibility and innovation. This can only be achieved through determining the linkages between goals, people and pedagogy in higher education. Ramani Describe to how Knowledge Management systems Creation of high Quality, its effect on meet requirements managerial for the whole company. This research reviews several topics as Knowledge Management System, KM Life Cycle. KM Building and Need for KM in Organizations etc. Researcher reached to several results, most notably is that Collaborative Knowledge Management system should be able to grow and adapt to changing business needs. It also explains that, decisions of Knowledge Management System should consider technological change. As well as, the organizations should be ready to accept an inevitability of change in this fast growing techno world. Additionally, it should keep the design of Knowledge Management system mission focused. It also should maintain common standards and stick to standards that have the highest level of industry support. K P Tripathi Show attempt to design and implement the knowledge based systems. Its effectiveness on business organization and taking management decisions related for the top management.The researcher has proposed the study on 'A Study of Knowledgebased System in Human Resource' with respect to Birla Corporation Limited. Thus, the researcher found that this paper have an impact on the important function of top management. In addition, the Expert System developed specifically helps HR managers to keep the control on working of the staff at various levels. The knowledge has importance of in the various management levels. Also, it has role in take administrative decision supportive to top management.

Studies related to Critical Success Factors are Manoucher et al propose a conceptual model for successful knowledge management in order to make solidarity among the results from previous studies that had commonly analyzed the effect and relation of effective elements of critical success factors in implementing knowledge management. The research has therefore presented a conceptual model for implementing knowledge management successfully in Tehran municipality as a case study. According to the conceptual model offered by this research, these critical success factors are dimensions of organizational culture, strategy and leadership, organizational structure, information technology infrastructure and human resources. At the end, it can be concluded that the produced model had sufficient and appropriate fit. As observed, factors of organizational structure and organizational culture have attained the most importance respectively among all 5 identified factors with the most significant regression coefficient on successful knowledge management. The next factors were IT infrastructure, strategy and leadership, and human resources. Subhacini et al aim to identifying a feasible and comprehensive the critical success factors of implementing knowledge management in Malaysian tourism sector. Researcher classify Critical Success Factors After reviewing several previous literature pertinent to critical success factors of KM to Top management leadership and support, Culture, Information technology (IT), Strategy and purpose, Organizational infrastructure, Measurement, Processes and activities, Motivational aids and Human resource management (HRM). There are plentiful proven records on the effectiveness of $\mathrm{KM}$ in various industries. However, tourism industry is still at impulsive stage and has been passive in adopting this approach due to lack of gearing between researchers and tourism. As a result, the primary research outline should focus on integrating a spirited KM approach based on the CFS as they control the process of KM implementation. Tourism industry needs to be prepared for these changes and challenges in order to add significant value towards the development of the country. Peyman et al 
Propose to examine the status of knowledge management $(\mathrm{KM})$ in selected Iranian academic research centre's (IARCs).In order to explore KM effect on the ARC's success and also identification of KM critical factors in ARC in Iran. Those centres include physics, chemical, drug, aerospace, nanotechnology, mechanic, aviation, and biotechnology research centres. The study then used factor analysis to extract critical factors of KM in ARC through 34 variables. These factors were: "human resource management and flexible structures," "KM architecture and readiness," "knowledge storage," "benchmarking," and "chief knowledge officer".This five critical success factors that had far greater contribution to the promotion of KM initiatives in Iranians' ARCs. Kuan Yew Wong propose a set of 11 CSFs which is believed to be more suitable for small and medium enterprises (SMEs).They are management leadership and support, culture, IT, strategy and purpose, measurement, organizational infrastructure, processes and activities, motivational aids, resources, training and education and HRM. The importance of the proposed CSFs was theoretically discussed and justified. The results showed that it supportive, thus providing a preliminary indication of the appropriateness of the proposed CSFs. In essence, this study is probably the first to provide an integrative perspective of CSFs for implementing $\mathrm{KM}$ in the SME sector. Murray E.Jennex and Lorne Olfman propose a framework for assessing knowledge management system (KMS) success models. The framework uses three criteria how well the model fits actual KMS success factors, the degree to which the model has a theoretical foundation and if the model can be used for two types of approaches to building a KMS. Based on their analysis of studies KMS success factors they identified potential success factors. The framework is then applied to four KMS success models found in the literature and is determined to be a useful framework for assessing KMS success models. They found that the proposed framework for assessing KMS Success models appears to be useful. It allows users to validate that the KMS success model they are using reflects observed factors that have been found to affect KMS success. This paper talked about critical success factors of KMS and its methodology. This concept give us the good background with him and explain to us extent of the similarities and differences between them and critical success factors of KM. Farida identify basic Critical Success Factors of Knowledge Management by using the lessons learned from early adopters. The researcher affirmed that the success of a KM initiative depends on many factors, some within our control, some not. Typically, critical success factors can be categorized into five primary categories leadership, culture, structure, roles, and responsibilities, information technology infrastructure and measurement.

\section{RESEARCH METHODOLOGY}

The goal of this research is to determine the impact of CSFs for the implementation of KM on the Deanships at King Abdul-Aziz University in Jeddah. The research community included eight deanships, with participation of male and female section, except for the Deanship of Scientific Research where only male section participated. The participating deanships were the Deanships of Community Services and Continuing Education, Admission and Registration, Students' Affairs, Library Affairs, E-Learning and Distance Education, Information Technology, Scientific Research, and Graduate Studies.

\subsection{Material}

The researcher used the questionnaire to collect data. The questionnaire consists of two parts. The first part pertained to demographic profiles and contained five questions related to Age, Gender, Educational Qualification, Experience and Deanship). The second part pertained to conceptual factors and contained 35 questions. This part revolves around general perception of KM and CSFs as well as the eight CSFs metrics. Four questions pertained to general perception toward KM and 31 questions pertained to CSFs metrics. Appendix has been divided these 31 questions into factors.

\subsection{Procedure}

The number of questionnaires returned from both male and female section was 220 (105 from male section and 115 from female section). It is worth mentioning that questionnaires were returned from all 15 deanships mentioned above. However, male section in the Deanship of E-Learning and Distance Education did not return any questionnaires. Therefore, the questionnaires distributed to participants in the Deanship of E-Learning and Distance Education has been excluded in the analysis, particularly in Deanships arrangement.

\subsection{Sample}

The research community is administrators in the deanships and totaled 1207 individuals. The study used a random sampling method; the total possible statistical sample was 1207, including 732 males and 475 females. A statistical table at the $95 \%$ confidence level and a margin of error of + or $5 \%$ was used to determine the sample size. [15]Therefore, the sample size was determined to be 291, including 176.479 $=176$ for representing half the male section population at a rate of $60.646 \%=61 \%$ and $114.517=115$ representing half the female section population at a rate of $39.353 \%=39 \%$.

\subsection{Statistical analysis}

The researcher used several tests, including t-tests and F-tests, to measure the effect of the general variables. A t-test is a parametric test of two independent samples. We use the t-test to test whether there is a significant difference between the means of responses of two independent populations. The Ftest in analysis of variance (ANOVA) is used to test whether there is a significant difference between the means of responses of more than two independent populations.

\subsection{Study Hypotheses}

In order to investigation the research problem, the following ten hypotheses tested:

H1: CSFs affect implementing $\mathrm{KM}$ at King Abdul-Aziz University.

H2: Strategy has a positive impact on implementing KM.

H3: Leadership has appositive impact on implementing KM.

H4: Organizational culture, structure, roles, and responsibilities have a positive impact on implementing KM

H5: Human resource management has a positive impact on implementing KM.

H6: Training has a positive impact on implementing KM.

H7: IT infrastructure has a positive impact on implementing KM

H8::Performance measurement has a negative impact on implementing KM.

H9: Knowledge management helps the exchange of knowledge between various levels. 
H10: KM helps managers make the best decisions

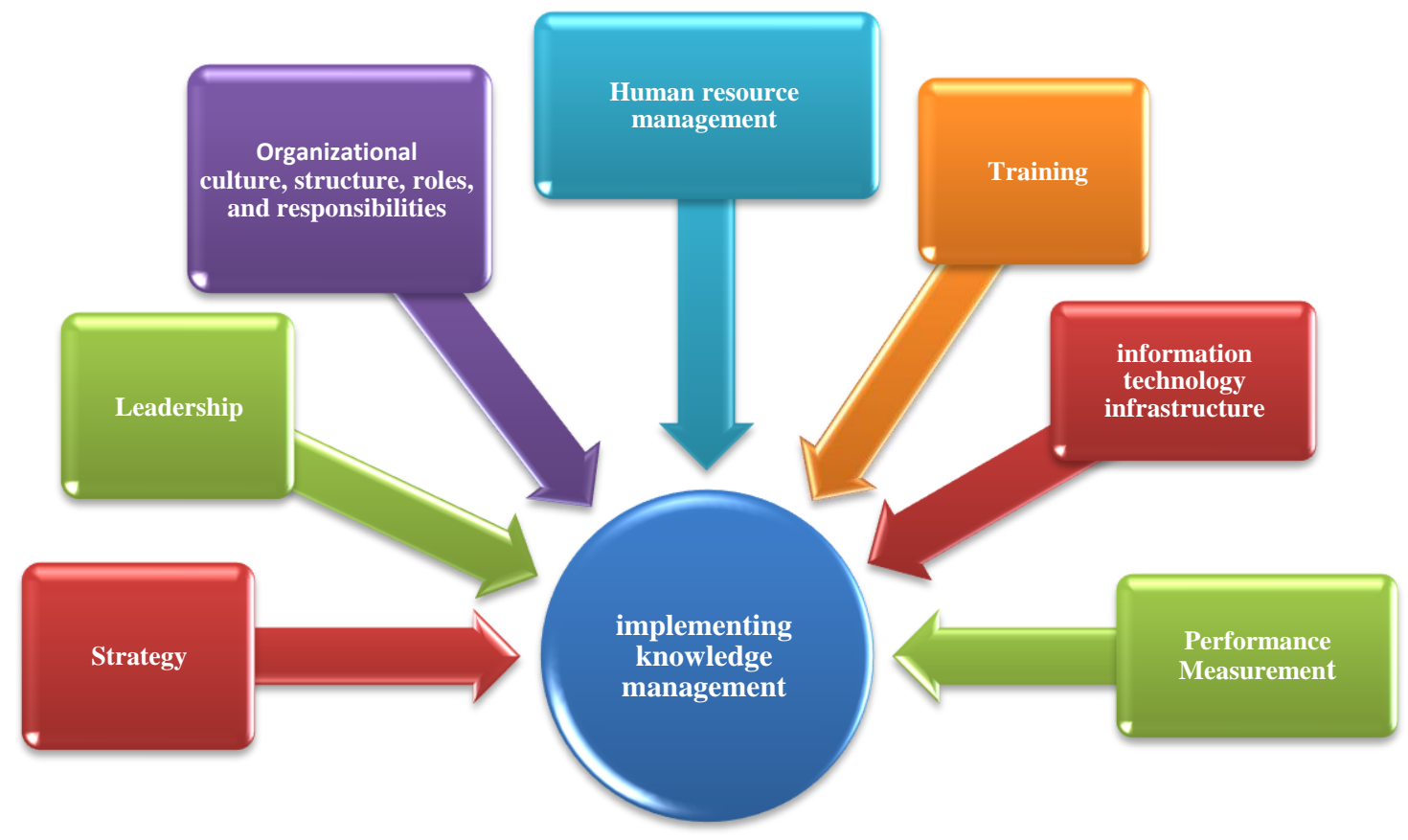

Fig 1: Fardous model to identify impact of CSFs for implementing KM

\subsection{The Nature of Critical Success Factors}

Studies differ on the number of success factors that have an impact on KM. The most prominent of these factors will be discussed in the following subsections.

\subsubsection{Leadership}

Leadership has a central role in the success of initiatives that are implemented internally in an organization. [11]

\subsubsection{Organizational Culture}

Organizational culture is comprised of values, standards, customs and beliefs that are shared by all employees of the organization. [8]

\subsubsection{Structure, roles and responsibilities}

Structure is reflected by the range of solutions that classify individuals by function. In addition, structure provides a way to coordinate functions. [14]

\subsubsection{Information technology infrastructure}

The organization must possess the infrastructure to enable its employees to share information and knowledge widely. Part of any KM initiative is a focus on having an information exchange platform rather than focusing on a particular software application. [11]

\subsubsection{Measurement}

Measurement reflects the extent to which the results of a particular process or activity match the desired objectives. [8]

\subsubsection{Strategy}

Strategy is one of the basic elements of CSFs. Strategy plays a role in directing the activities of the organization in general and $\mathrm{KM}$ in particular. [13, 14]

\subsubsection{Human resource management}

Human resource management (HRM) can have a significant positive or negative impact on the management of knowledge. $[8,14]$

\subsubsection{Training}

Training about CSFs that are essential to the success of KM is important. Training leads to better understanding of the concept of KM better. [8]

\section{RESULTS}

In this section, the researcher will show the descriptive statistics for the general variables. In addition, addresses data from a statistical point through the following topics: measuring reliability, descriptive statistics for questions (Likert scale), relationship between factors, and the effect of the general variables.

\subsection{Measures of Reliability}

Alpha coefficient ranges in value from 0 to 1 . The higher the value, the more reliable the generated scale is. Cronbach's Alpha coefficient is used to evaluate the reliability of the scale for the considered factors. The values of Cronbach's alpha for the scale are very near to 1 , and for all factors are more than 0.65 , which indicates the reliability of the considered scale and its factors.

\subsection{Descriptive Statistics for Questions in the form of Likert Scale}

Table 1 shows that the priority of the factors according to their means. The first four factors are:

- Human Resource Management

- Information Technology Infrastructure

- Leadership

- Training.

\subsection{Relation between factors}

Pearson correlation coefficient is used in measuring the value of the relationship between factors. Table 2 gives the correlation between Perception toward knowledge management and each of critical success factors. 
The correlation coefficients presented in Error! Reference source not found. are significant at the 0.01 level. Since the p-value is less than 0.001 for each CSF, this means that there is significant relation at level 0.001 between perception toward knowledge management and each of CSFs. This proves the following hypotheses:

- Strategy has positive impact on implementing knowledge management.

- Leadership has positive impact on implementing knowledge management.

- Culture, structure, roles, and responsibilities have positive impact on implementing knowledge management.

- Human resource management has positive impact on implementing knowledge management.
- Training and education has positive impact on implementing knowledge management.

- Information technology infrastructure has positive impact on implementing knowledge management.

The impact of the factor "Performance Measurement" on implementing knowledge management is positive, not negative.

\subsection{The Effect of the General Variables}

To study the effect of the general variables on the opinions of the respondents, researchers test some hypotheses by using Ttest and F- test based on sample of all variable. The table explains variables and the test and the result all variable as shown in Table 3.

Table 1. Summary of the Means and std. Deviation of the Factors

\begin{tabular}{|l||c|c|c|c||}
\hline \multicolumn{1}{|c||}{ Factors } & $\begin{array}{c}\text { Weighted } \\
\text { mean }\end{array}$ & $\begin{array}{c}\text { Std. } \\
\text { deviation }\end{array}$ & $\begin{array}{c}\text { Overall } \\
\text { response }\end{array}$ & Priority \\
\hline \hline $\begin{array}{l}\text { 1. Perception toward Knowledge } \\
\text { Management }\end{array}$ & 1.86 & 0.86 & agree & 5 \\
\hline 2.Strategy & 2.33 & 0.88 & agree & 3 \\
\hline $\begin{array}{l}\text { 3. Leadership } \\
\text { 4. Organizational culture, structure, roles, } \\
\text { and responsibilities }\end{array}$ & 2.05 & 1.04 & agree & 6 \\
\hline $\begin{array}{l}\text { 5. Human resource management } \\
\text { 6. Training }\end{array}$ & 1.96 & 1.20 & agree & 1 \\
\hline 7. Information technology infrastructure. & 1.99 & 0.95 & agree & 2 \\
\hline 8. Performance Measurement. & 2.52 & 0.98 & agree & 7 \\
\hline \hline
\end{tabular}

Table 2. Correlation Coefficient between Perception toward Knowledge Management and each Critical Success Factor (N=220)

\begin{tabular}{|c|c|c|}
\hline \multicolumn{2}{|c|}{ Critical Success Factors } & 1. Perception toward Knowledge \\
\hline \multirow{2}{*}{ 2.Strategy } & Pearson correlation & $0.535 * *$ \\
\hline & Sig. (p-value) & 0.000 \\
\hline \multirow{2}{*}{ 3. Leadership } & Pearson correlation & $0.558 * *$ \\
\hline & Sig . (p-value) & 0.000 \\
\hline \multirow{2}{*}{$\begin{array}{l}\text { 4. Organizational culture, } \\
\text { structure, roles, and } \\
\text { responsibilities }\end{array}$} & Pearson correlation & $0.349 * *$ \\
\hline & Sig . (p-value) & 0.000 \\
\hline 5. Human resource management & Pearson correlation & $0.495 * *$ \\
\hline
\end{tabular}




\begin{tabular}{|l|c||c|}
\hline \multirow{2}{*}{ 6. Training } & Sig · (p-value) & 0.000 \\
\cline { 2 - 3 } & Pearson correlation & $0.362^{* *}$ \\
\cline { 2 - 3 } $\begin{array}{c}\text { 7.Information technology } \\
\text { infrastructure }\end{array}$ & Sig · (p-value) & 0.000 \\
\hline \multirow{2}{*}{ 8. Performance Measurement. } & Pearson correlation & $0.486^{* *}$ \\
\cline { 2 - 3 } & Sig . (p-value) & 0.000 \\
\cline { 2 - 3 } & Sig . (p-value) & $0.396^{* *}$ \\
\hline
\end{tabular}

Table 3. Summary of the Effect of the General Variables

\begin{tabular}{|c|c|c|}
\hline General variables & The test & The result \\
\hline 1. Age & $\begin{array}{l}\text { F-test (ANOVA), (More than two } \\
\text { independent samples) }\end{array}$ & $\begin{array}{l}\text { The young people more agreeable than } \\
\text { old people }\end{array}$ \\
\hline 2. Gender & T-test (Two independent samples test) & $\begin{array}{l}\text { The females are more agreeable in } \\
\text { relation to these factors than males. }\end{array}$ \\
\hline 3. Educational Qualification & $\begin{array}{l}\text { F-test (ANOVA), (More than two } \\
\text { independent samples) }\end{array}$ & $\begin{array}{l}\text { The least qualified people are more } \\
\text { agreeable than people that are more } \\
\text { qualified. }\end{array}$ \\
\hline 4. Experience (Years) & $\begin{array}{l}\text { F-test (ANOVA), (More than two } \\
\text { independent samples) }\end{array}$ & $\begin{array}{l}\text { The opinions of the people with } \\
\text { "Above } 30 \text { years" is "Neutral or } \\
\text { Disagree," while the means opinion of } \\
\text { the people with other years of } \\
\text { experience is "Agree." }\end{array}$ \\
\hline 5. Deanships & $\begin{array}{l}\text { F-test (ANOVA), (More than two } \\
\text { independent samples) }\end{array}$ & $\begin{array}{l}\text { There is significant difference between } \\
\text { the means of individual responses due } \\
\text { to different Deanships. }\end{array}$ \\
\hline
\end{tabular}

\section{CONCLUSION}

This study aimed to measure the impact of Critical Success Factors for implementing knowledge management at King Abdul-Aziz University. It was applied to administrators at the deanships (male and female section).A questionnaire was used to collect data.

After analyzing the data, the researcher concluded that all the factors have a positive impact on the implementation of knowledge management. This result corresponds to the researcher's hypotheses, with the exception of the measurement factor hypothesis. Based on the weighted mean, the prioritized order of the factors was Human Resource Management; Information Technology Infrastructure; Leadership; Training; Strategy; Organizational culture, Structure, Roles, and Responsibilities; and finally Performance measurement. It was noted from the analysis that the overall response of the statements and for the whole factors was "Agree," which means that the respondents agree about the role of Perception toward Knowledge Management and all Critical Success Factors.
In descending order, the deanships that received the top responses for male and female section were the Deanship of Information Technology, Deanship of Admission and Registration, and Deanship of Community Services and Continuing Education for male section and the Deanship of Admission, and Registration, Deanship of Information Technology and Deanship of Library Affairs for female section. The response scores were lower for the Deanship of Library Affairs for male section and the Deanship of Community Services and Continuing Education for female section.

The researcher used several tests, including t- tests and Ftests, to measure the effect of the general variables. It found that there is no significant difference for some factors; however, there is significant difference between the means of individual responses due to different classes of age, gender, educational qualification, experience, and deanship.Additionally, the researcher used the Pearson correlation coefficient to measure the value of the relationship between the perception toward knowledge management and each critical success factor. Accordingly, it turns out that there 
is a significant relationship at level 0.001 between perception toward knowledge management and each critical success factor because, the p-value is less than 0.001 for each of the critical success factors.

\section{REFERENCES}

[1] Rodger, M. Good Knowledge Management System, Bad Shared Knowledge: What happens to trust when experts share erroneous knowledge with novice KMS USERS?, Advances in Management, Vol. 5.1 (2012): 9-13.

[2] Mehrabani, Shadi Ebrahimi, and Maziar Shajari, Knowledge Management and Innovation Capacity, Journal of Management Research, Vol. 4.2 (2012): 164177.

[3] OPREA, Mihaela, An Agent-Based Knowledge Management System for University Research Activity Monitoring, Informatica Economica, Vol. 16.3 (2012): 136-147.

[4] Aktharsha, U. Syed, H. Anisa, and S. Dawood Ali, The Usage Behavior of Knowledge Management System in Hospitals, The IUP Journal of Knowledge Management, Vol. 10.2 (2012): 22-44.

[5] LUBEGA, JUDE T., WALTER OMONA, and T. H. E. O. VAN DER WEIDE, Knowledge Management Technologies and Higher Education Processes: Approach to Integration for Performance Improvement, International Journal of Computing and ICT Research, Vol. 5 (2011): 55-68.

[6] Gopal, Ramani, and P. A. Joy, Creation of Knowledge Management System, Advances In Management, Vol. 4.11 (2011): 7-14.

[7] Tripathi, K P, Design and Implementation of Knowledge-based Systems in Human Resource, International Journal of Advanced Research in Computer Science, Vol. 2.3 (2011): 44-46.

[8] Wong, Kuan Yew, Critical success factors for implementing knowledge management in small and medium enterprises, Industrial Management \& Data Systems, Vol. 105.3 (2005): 261-279.

[9] Jennex, Murray E., and Lorne Olfman, Assessing knowledge management success/effectiveness models, Proceedings of the 37th Hawaii International Conference on System Sciences, Vol. 8 (2004): 1-10.

[10] Irma Becerra Fernandez and Rajiv Sabherwal, Knowledge Management: Systems and Processes (M.E. Sharpe, 2010), 5-6-17-18-24-25-26-41-62.

[11] Hasanali, Farida, Critical success factors of knowledge management, Knowledge Management Advantage, (2002).

[12] Akhavan, Peyman, Reza Hosnavi, and Mohammad E. Sanjaghi, Identification of knowledge management critical success factors in Iranian academic research centers, Education, Business and Society: Contemporary Middle Eastern Issues , Vol. 2.4 (2009): 276-288.

[13] Subramaniam, Subhacini, Sharmila Rani Moganadas, and Kalaiarasi Sonaimuthu Anbananthan, Critical Success Factors of Knowledge Management in theMalaysian Tourism Industry, Proceedings of the International Conference on Intellectual Capital, Knowledge Management \& Organizational Learning. (2011): 521-528

[14] Ansari, Manoucher, Hossein Rahmany Youshanlouei, and Mohammad Mirkazemi Mood, A Conceptual model for success in implementing knowledge management: A case study in Tehran municipality, Journal of Service Science and Management, Vol. 5 (2012): 212-222.

[15] Universal Accreditation Board (2003), Table for Determining Random Sample Size from a Given Population, New York: Universal Accreditation Board

[16] KingAbdulazizUniversity,OurHistory,http://www.kau.ed u.sa/Content.aspx?Site_ID=0\&lng=EN\&cid=2384 access date Mar. 31, 2014.King Abdulaziz University, Vision AndObjectives,http://www.kau.edu.sa/Content.aspx?Site $\mathrm{ID}=0 \& \operatorname{lng}=\mathrm{EN} \& \mathrm{cid}=2385$ access date Mar. 31, 2014 